\title{
Influence of variable stiffness shoes in sports performance and protection of lower extremity injury
}

Jee-Chin Teoh*, Wen-Min Chen, Taeyong Lee

From 3rd Congress of the International Foot and Ankle Biomechanics Community

Sydney, Australia. 11-13 April 2012

\section{Background}

Footwear is an effective biomechanical solution to lower extremity joint problems. Variable stiffness shoe (VSS) is designed. It has been proved to reduce knee internal

abduction (external adduction) moment [1]. This helps to slow down progression of medial knee osteoarthritis (OA) [2]. However, there is no study on the effects of VSS on lower extremity during dynamic activities

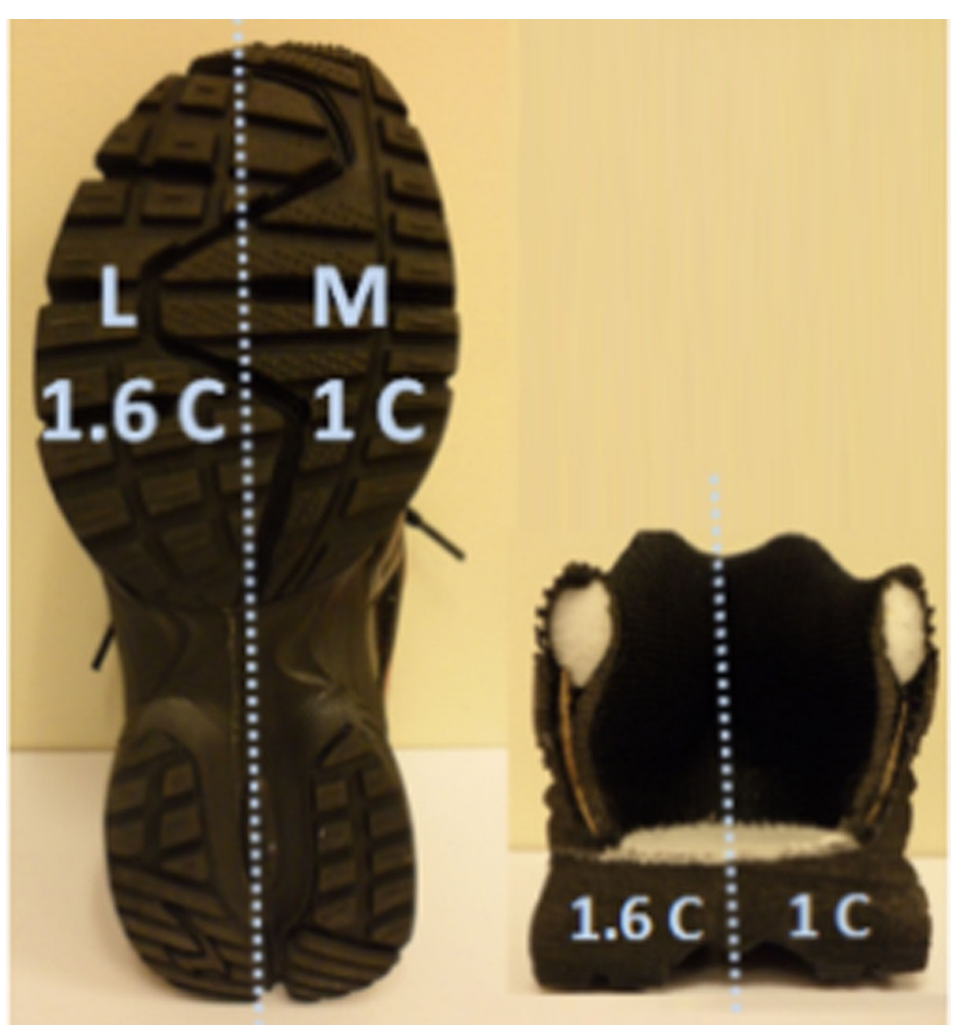

Figure 1 Images of shoe bottom and shoe cross section showing lateral (L) and media (M) soles. 
Table 1 Table compares only the averages of kinematics (angles) and kinetics (moments and forces) data that are statistically significant $(p<0.05)$ during the dynamic activities.

\begin{tabular}{llllll}
\hline Activity & Joint & Variable Name & Control & VSS & \%difference \\
\hline Walking & Knee & Max adduction moment (\%BWxHt) & 0.37 & 0.35 & -5.994 \\
Walking & & Max anterior force at push off (\%BW) & 19.73 & 20.97 & 6.302 \\
Running & Knee & Max adduction moment (\%BWxHt) & 1.04 & 0.88 & -14.716 \\
Running & & Max posterior force (\%BW) & -24.50 & -28.93 & 18.072 \\
Running & & Max anterior force (\%BW) & 29.02 & 30.78 & 6.078 \\
Stop Jumping & Knee & Max adduction moment (\%BWxHt) & 0.83 & 0.67 & -18.661 \\
Stop Jumping & & Max posterior force (\%BW) & -67.67 & -73.33 & 8.373 \\
\hline
\end{tabular}

besides walking. Influence of VSS in sports performance is also yet to be examined. This study aims to investigate the biomechanical influence of VSS on lower extremity during dynamic activities and to assess the potential of VSS in improving sports performance.

\section{Materials and methods}

15 female and 15 male subjects walked in 2 conditions: VSS and Control. VSS had a lateral sole 1.6 times stiffer than medial (Figure 1). The optimized ratio was obtained from finite element analysis of a simplified 2D knee model. Control had uniform stiffness outsole.3D kinematic and kinetic analysis was conducted during walking, running, stop jumping and lateral hopping. Rating on footwear comfort was also performed.

\section{Results}

Increased posterior force during running and stop jumping (Table 1) ensured controlled gait termination and reduced the risk of fall. Increased anterior force during walking and running (Table 1) increased forward propulsion and acceleration. Knee internal abduction moment was generally reduced (Table 1). This showed potential of VSS as sportswear that helped to relieve medial knee loading in more vigorous activities such as running, stopping and jumping. Kinetic data and comfort data showed that VSS did not change gait kinematics much. Rating differences were all insignificant $(p<0.05)$. The stiffness variation in VSS was hardly noticeable. Shoe comfort was not compensated in VSS.

\section{Conclusion}

The study demonstrated great potential of VSS in improving sports achievement and protecting knee. Outsole configuration can be further modified by varying outsole stiffness along anteroposterior axis for better performance and protection.

\section{References}

1. Erhart JC, Mundermann A, Elspas B, et al: A variable-stiffness shoe lowers the knee adduction moment in subjects with symptoms of medial compartment knee osteoarthritis. J Biomech 2008, 41:2720-2725.

2. Miyazaki T, Wada M, Kawahara $H$, et al: Dynamic load at baseline can predict radiographic disease progression in medial compartment knee osteoarthritis. Ann Rheum Dis 2002, 61:617-622.

doi:10.1186/1757-1146-5-S1-O50

Cite this article as: Teoh et al:: Influence of variable stiffness shoes in sports performance and protection of lower extremity injury. Journal of Foot and Ankle Research 2012 5(Suppl 1):O50.
Submit your next manuscript to BioMed Central and take full advantage of:

- Convenient online submission

- Thorough peer review

- No space constraints or color figure charges

- Immediate publication on acceptance

- Inclusion in PubMed, CAS, Scopus and Google Scholar

- Research which is freely available for redistribution

Submit your manuscript at www.biomedcentral.com/submit 